\section{A New ISC Service: The Bibliography of Seismic Events}

\section{by D. Di Giacomo, D. A. Storchak, N. Safronova, P. Ozgo, J. Harris, R. Verney, and I. Bondár}

Online Material: Journals in the ISC Event Bibliography.

\section{INTRODUCTION}

The International Seismological Centre (ISC) is a not-forprofit organization with the primary mission of producing the definitive summary of the seismicity of the Earth (ISC Bulletin; ISC, 1964-2013). This is achieved thanks to a unique international cooperation in the seismological community that allows the ISC to collect, integrate, and finally process seismological bulletins (location parameters, station data, moment tensor solutions, felt reports, etc.) from approximately 130 agencies worldwide. Seismic (earthquakes or man-made) events parameters and station data are publicly available via the ISC website (www.isc.ac.uk, last accessed January 2014).

In 2012 we started to set up a new database to link parametric data related to seismic events (earthquakes or anthropogenic events) in the ISC Bulletin to publications considering specific seismic events. Such association is often needed by researchers in order to identify and gather information related to seismic events. Usually bibliographic searches (such as Google Scholar) are used by typing a text string containing a name for the seismic event or the region and date it occurred. Such a search may need to be repeated several times to account for all possible transliterations of a place name, several different ways of specifying a date and a variety of names of the area where the seismic event has occurred. For example, the great Sumatra earthquake of 2004 could be searched as "SumatraAndaman," "Banda-Aceh," "Aceh-Sumatra," etc. The results then have to be merged and the duplicates removed. The procedure is daunting and often leads to unsatisfactory results.

The ISC Event Bibliography database allows users to search for publications linked to seismic events in the ISC Bulletin. This association enables users to perform searches based on event parameters (e.g., location and time of the event) and/ or publications parameters (e.g., author name, journal, year of publication). A schematic view of the search engine behind the ISC Event Bibliography is shown in Figure 1.

The database includes publications for which we identified events in the ISC database and is mostly composed of dedi- cated studies on specific events. Earthquakes belonging to a catalog (like the GCMT, EHB, ISC-GEM, etc.) are not linked to the Event Bibliography, nor are the publications that deal with seismicity of specific regions or include large regional earthquake catalogs.

With rare exceptions, we included only those publications that contained English titles and abstracts. We make no judgment of the quality of scientific articles. We continue to include further entries and invite our users to help us with necessary updates (see www.isc.ac.uk/event_bibliography/submit.php/, last accessed November 2013).

The publications linked to seismic events are not limited to seismology. They cover a broad range of disciplines including, but not limited to, earthquake engineering, tectonics, structural geology, geodesy, remote sensing, nuclear test monitoring, tsunami, landslides, environmental studies, coastal science, natural disasters, hydrology, geochemistry, atmospheric sciences, and geomagnetism. This feature makes the Event Bibliography an attractive tool for multidisciplinary studies and useful for researchers and students from different fields. We expect that this ISC product will also be helpful in facilitating the work of authors, reviewers, and journal editors during the entire process of scientific article publication.

\section{COMPOSITION OF THE EVENT BIBLIOGRAPHY DATABASE}

The database is a continuation and extension of the Bibliography of Seismology (ISC, 1965-1995), which was produced at the ISC between 1965 and 1995. The Bibliography of Seismology is a collection of articles (including Ph.D. Theses, news, and reports not subject to a standard review process) related to seismological studies where users can perform searches for a string in the database (title, author, journal, and keywords) and without returning the events links. It also includes references compiled by the Canadian Dominion Observatory in the period 1956-1964, although these references are not complete (e.g., usually only author list and title are available). The Bibliography of Seismology, although ceased in 1995, is still available at www.isc.ac.uk/projects/bibliography/ (last accessed November 2013).

Exploiting the references collected by the ISC since 1970s, in year 2000 the ISC linked about 4000 publications in the period 1971-1995 with the ISC event identifier. The seismicevent list linked to publications was made available at the ISC website (now replaced by the Event Index, www.isc.ac.uk/event bibliography/eventindex.php, last accessed November 2013), 


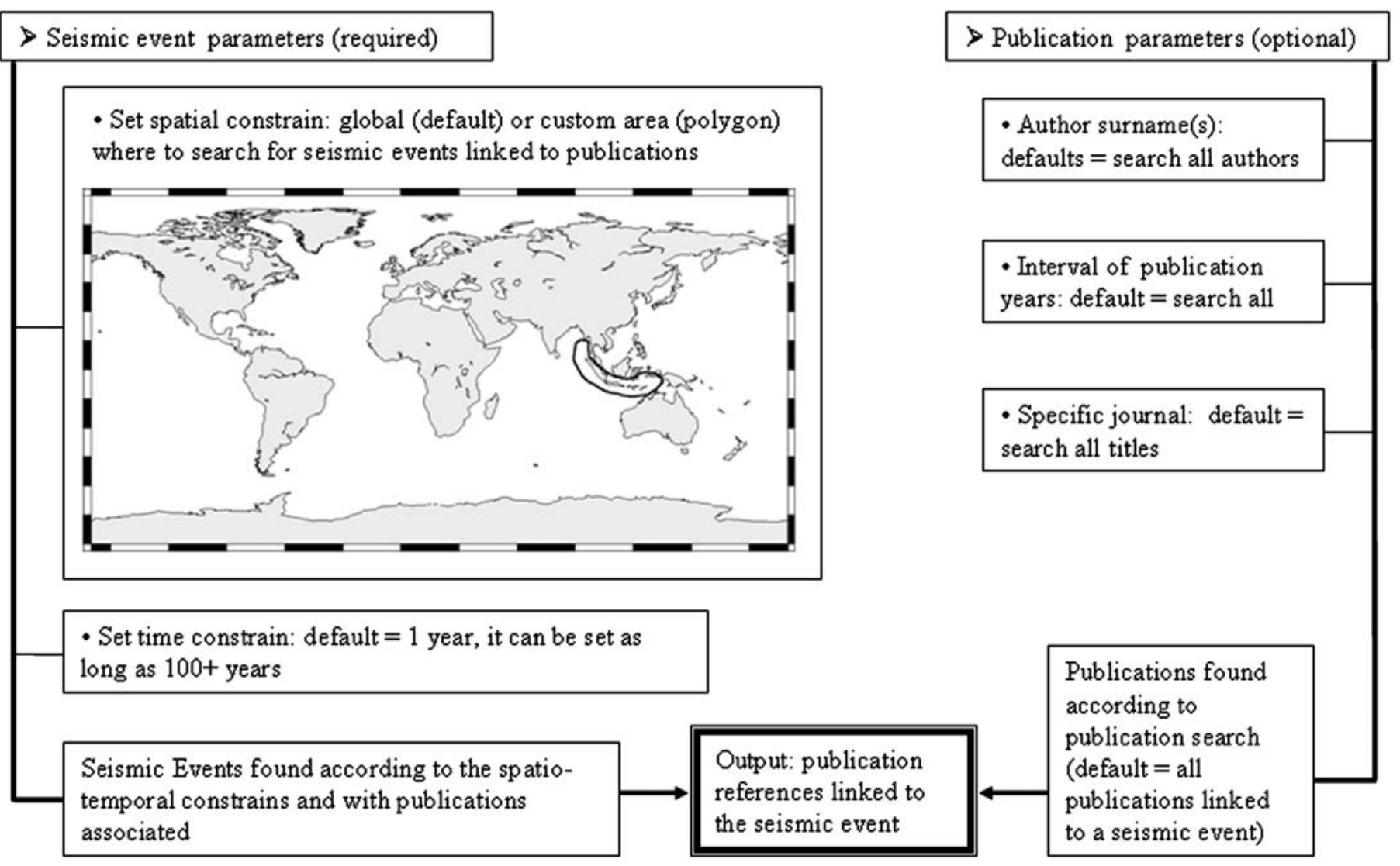

A Figure 1. Schematic overview of the Event Bibliography database. The association between seismic events and publications allows users to limit the spatiotemporal parameters of seismic events and, eventually, also the publication parameters. As an example, a polygon around the Indonesian archipelago is shown on the map.

and such associations are preserved in the current Event Bibliography, which is described in more detail in the following.

In order to resume and improve this service, in 2012 we started to link ISC event identifiers to publications that deal with specific seismic events and published in the period 1996 to present. This was necessary in order to fill the gap in our publication record after the Bibliography of Seismology ceased in 1995. In addition to that, other publications in different periods were also added:

- references having only authors and title in the old Bibliography of Seismology in the period 1956-1972 were completed and linked to the ISC event identifier;

- references based on the ISC-GEM Catalog (see Storchak et al., 2013) work of Lee and Engdahl (2013);

- references based on the work of Allen et al. (2009) for the ShakeMaps Atlas.

Hence, about 50 years of publications considering earthquakes or man-made events are available in the Event Bibliography database. Figure 2 summarizes the event-publication associations. As of November 2013, the Event Bibliography database contains over 15,000 references (Fig. 2a) from about 500 titles. For most of the recent publications, we include the Digital Object Identifier (DOI, www.doi.org or www.crossref .org, last accessed November 2013), allowing users direct access to the paper at the journal website or to the link to the journal home page. In general, most of the events have only a few links to publications (Fig. 2b), but a few have a considerable amount of articles associated (e.g., the Wenchuan earthquake of 12 May 2008 with more than 850 articles linked, as of November 2013). Although the older publications in the database cover the 1950s, some events were also studied several decades after the event occurrence, so that significant earthquakes at the beginning of twentieth century (Fig. $2 \mathrm{~b}, \mathrm{c}$ ) are also present (e.g., 1906 San Francisco earthquake).

Figure 3 shows the spatial distribution of the seismic events coded by number of publications, as well as the top 50 events with most publications associated. Not surprisingly, the events with most publications occurred in Japan, California, and the Euro-Mediterranean region. The event name we adopted is considered the most popular for a given event, although different names may be found in the literature.

The database is updated on a monthly schedule as new publications become available. We follow several journals (ㅌ) see the electronic supplement for the list of journals currently considered). The journal selection was done in order to encompass a wide range of disciplines related to geoscience and available at various databases (ㅌ) see the electronic supplement). Other journals can be added to the list if required. 
(a)

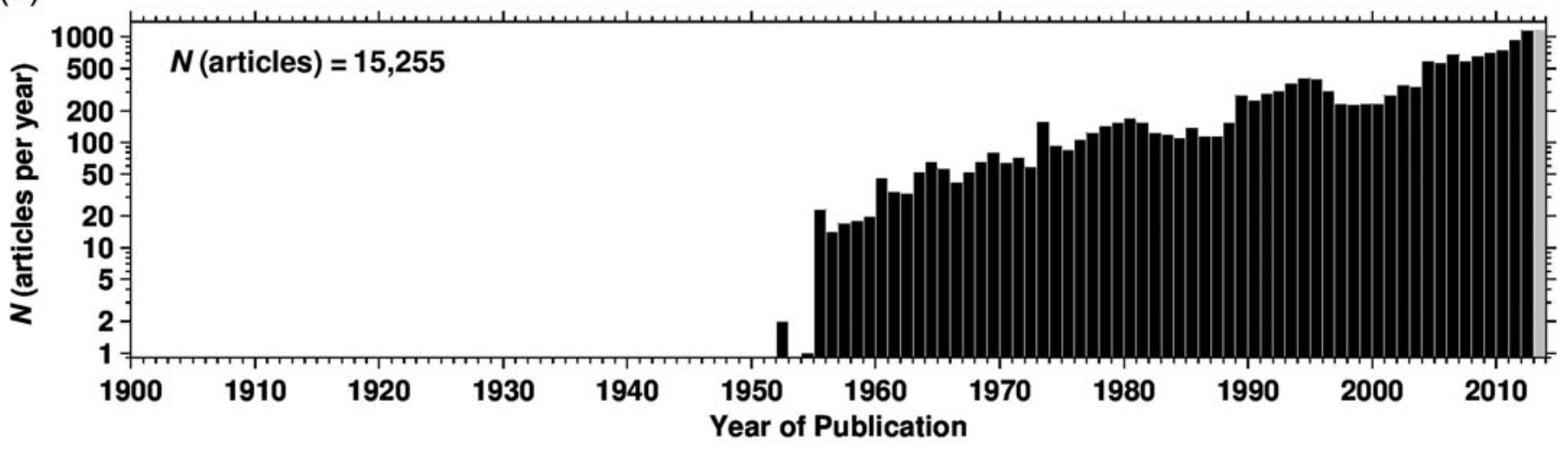

(b)

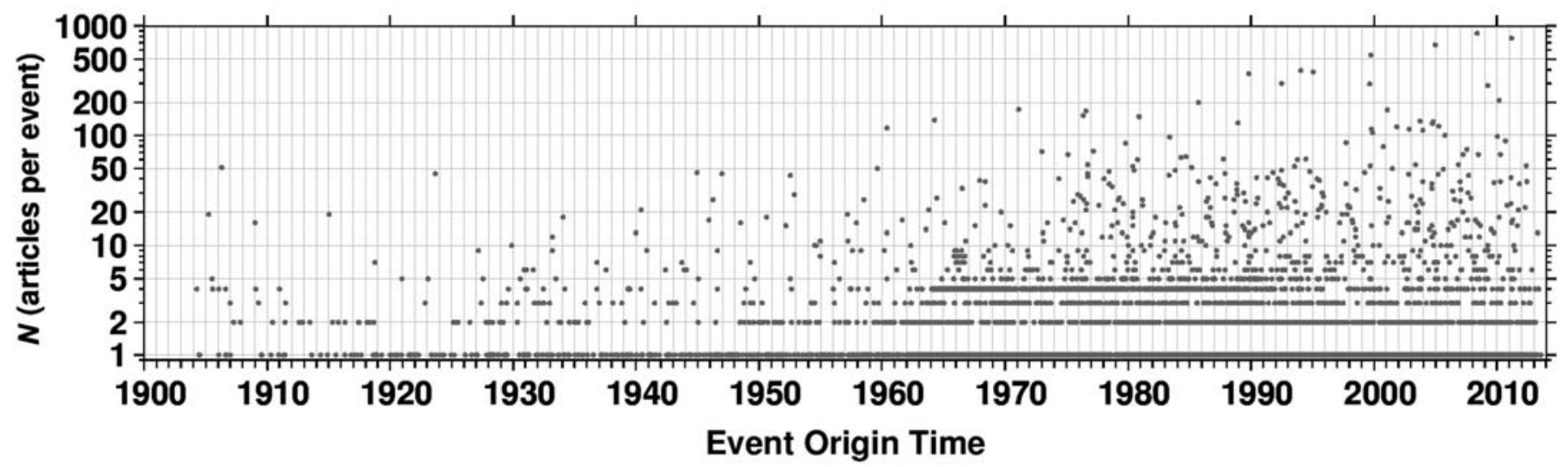

(c)

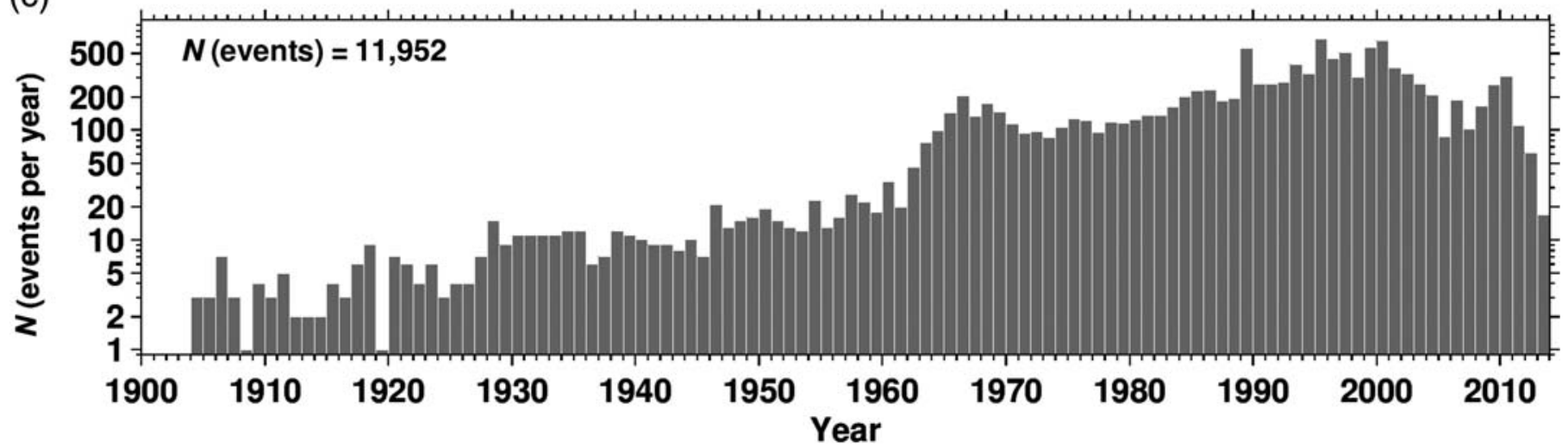

A Figure 2. (a) Annual number of publications linked (gray covers the current year in which publications are still being collected) to events; (b) timeline of events associated with at least one paper; (c) annual number of events linked to articles. Updates of this information will be available at www.isc.ac.uk/event_bibliography/overview.php/ (last accessed November 2013) or http://colossus.iris.washington.edu/ event_bibliography/overview.php/ (last accessed November 2013).

For the selected journals we either check the Electronic Table of Contents (E-ToC) e-mail alerts or, if E-ToC are not available, the ToC are checked after a given period of time since the last issue has passed (ㅌ) the list of journals periodically checked is available at the bottom of the electronic supplement). The () first column in the electronic supplement lists the provider of the E-Toc e-mail alerts. By inspecting the new publications of a journal, staff at the ISC look first for papers dealing with earthquakes or anthropogenic events and then inspect the article (limiting to Abstract if full access is not available) in order to associate the reference with the ISC event identifier(s). As mentioned before, we do not usually associate events belonging to large datasets.

In the future we hope to cooperate with publishers to set up a system that allows authors to link (or provide basic information to link) newly submitted papers with events in the 


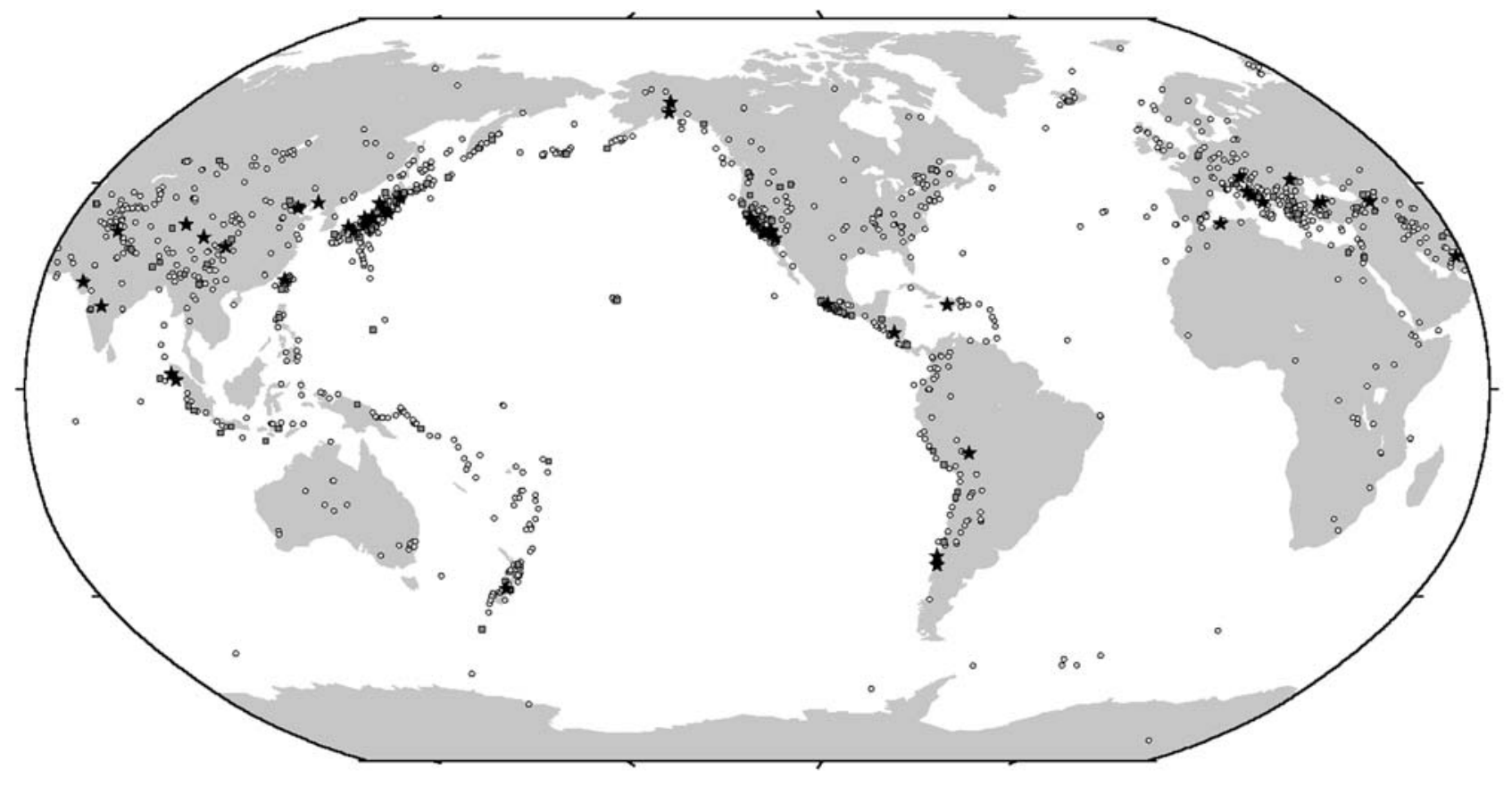

"The most studied events"

Event origin time

2008-05-12 06:27:59 857 WENCHUAN2008

2011-03-11 05:46:23

2004-12-26 00:58:52

1999-09-20 17:47:16

1994-01-17 12:30:54

1995-01-16 20:46:51

1989-10-18 00:04:14

1992-06-28 11:57:35

2009-04-06 01:32:42

2010-02-27 06:34:13

1985-09-19 13:17:50

1971-02-09 14:00:40

2001-01-26 03:16:40

1976-07-27 19:42:53

1976-05-06 20:00:12

1980-11-23 18:34:52

1964-03-28 03:36:13

2004-10-23 08:55:58

1988-12-07 07:41:24

2004-09-28 17:15:24

2005-03-28 16:09:35

2001-11-14 09:26:10
$N$ Code

775 TOHOKU2011

668 SUMATRA2004

540 CHI-CHI1999

393 NORTHRIDGE1994

381 SHYOGO1995

368 LOMAPRIETA1989

300 LANDERS1992

297 IZMIT1999

285 LAQUILA2009

210 MAULE2010

201 MEXICOCITY1985

173 SANFERNANDO1971

168 TANGSHAN1976

153 FRIULI1976

149 CAMPANIA1980

138 ALASKA1964

135 TOKACHI-OKI2003

134 MID-NIIGATA2004

131 ARMENIA1988

129 PARKFIELD2004

121 NIAS2005

120 KUNLUN2001
Event origin time

2002-11-03 22:12:41

1999-10-16 09:46:45

2003-12-26 01:56:53

1999-11-12 16:57:19

2005-10-08 03:50:35

2010-01-12 21:53:10

1983-05-26 02:59:58

2010-09-03 16:35:46

1997-09-26 09:40:25

1979-10-15 23:16:57

2000-10-06 04:30:17

2007-07-16 01:13:21

1977-03-04 19:21:54

1972-12-23 06:29:42

2008-06-13 23:43:46

2010-04-13 23:49:37

1975-02-04 11:36:05

2007-03-25 00:41:57

1984-09-13 23:48:51

1984-04-24 21:15:19

1987-10-01 14:42:18

1994-06-09 00:33:16

1980-10-10 12:25:22

1993-09-29 22:25:50

1976-09-15 03:15:18
$N$ Code

115 DENALI2002

114 HECTOR-MINE1999

112 BAM2003

107 DUZCE1999

101 KASHMIR2005

98 HAITI2010

97 SEAOFJAPAN1983

89 DARFIELD2010

86 UMBRIA-MARCHE1997B

85 IMPERIAL1979

79 TOTTORI2000

75 CHUETSU-OKI2007

72 ROMANIAN1977

71 MANAGUA1972

67 IWATE-MIYAGI2008

67 YUSHU2010

67 HAICHENG1975

67 NOTO-HANTO2007

64 NAGANO1984

63 MORGAN1984

61 WHITTIER1987

61 BOLIVIA1994

60 ELASNAM1980

60 LATUR1993

54 FRIULI1976D

A Figure 3. Top: Locations of the ISC events in the Event Bibliography. The gray circles refer to events with less than 20 associated publications, dark gray squares to events having 20-54 associated publications, and black stars refer to the 50 events listed below the map. Bottom: The first 50 seismic events and the number of associated publications $(N)$. Updates of this information will be available at www.isc.ac.uk/event_bibliography/overview.php/ or http://colossus.iris.washington.edu/event_bibliography/overview.php/.

ISC database. This will help to facilitate the process of updating the Event Bibliography.

Tables 1 and 2 list the first 20 journals and authors, respectively, with most articles linked to events in the ISC
Bulletin. Note that Table 2 is merely a rank based on the publications linked to ISC events. Authors can check for missing papers or missing associations and are encouraged to use the publication submission form or contact us in such cases. 


\begin{tabular}{|c|c|}
\hline \multicolumn{2}{|c|}{$\begin{array}{l}\text { Table } 1 \\
\text { List of The First } 20 \text { Journals with the Most Publications } \\
\text { Associated with the Event Bibliography as of November } \\
2013\end{array}$} \\
\hline Journal & $\begin{array}{c}N \\
\text { (articles) }\end{array}$ \\
\hline Bulletin of the Seismological Society of America & 1860 \\
\hline Journal of Geophysical Research & 964 \\
\hline Geophysical Research Letters & 935 \\
\hline Tectonophysics & 585 \\
\hline Geophysical Journal International & 545 \\
\hline Pure and Applied Geophysics & 417 \\
\hline Earth, Planets Space & 408 \\
\hline Earthquake Spectra & 405 \\
\hline Seismological Research Letters & 356 \\
\hline Acta Seismologica Sinica & 287 \\
\hline $\begin{array}{l}\text { Bulletin of the Earthquake Research Institute, } \\
\text { Tokyo University }\end{array}$ & 241 \\
\hline Eos, Transactions American Geophysical Union & 232 \\
\hline Annals of Geophysics & 220 \\
\hline $\begin{array}{l}\text { Zisin (Journal of the Seismological Society of } \\
\text { Japan, 2nd ser.) }\end{array}$ & 206 \\
\hline Chinese Journal of Geophysics & 197 \\
\hline Nature & 196 \\
\hline Natural Hazards and Earth System Science & 192 \\
\hline Natural Hazards & 182 \\
\hline Physics of the Earth and Planetary Interiors & 176 \\
\hline Journal of Seismology & 175 \\
\hline
\end{tabular}

\section{SEARCHING THE EVENT BIBLIOGRAPHY}

The ISC Event Bibliography offers the possibility of making searches by using event and/or publication parameters (www isc.ac.uk/event_bibliography/bibsearch.php, last accessed November 2013). The spatial search is global by default or polygons can be drawn on a Google map. The temporal search is limited to one year by default, but it can be expanded to $100+$ years. Additionally, users can search also for publications in a specific journal and/or author(s) and year of publication. Alternatively to the search based on event parameters, users can also look at the Event Index webpage (www.isc.ac.uk/event bibliography/eventindex.php).

For each event, the output is comprised of

1. an event header line, which includes the ISC event identifier, the preferred hypocenter along with the agency, the preferred magnitude estimation, the total number of publications linked to the event, and, finally, if available, the Event code (links to the ISC Bulletin for the events found are also provided); and

2. references in a format widely accepted by most journals.
Table 2

List of the First 20 Authors with the Largest Number of EventOriented Articles Included in the ISC Event Bibliography as of November 2013

\begin{tabular}{|lc|}
\hline \multicolumn{1}{c}{ Author } & N (articles) \\
\hline Kanamori, H. & 163 \\
Satake, K. & 87 \\
Bürgmann, R. & 74 \\
Hasegawa, A. & 74 \\
Lay, T. & 73 \\
Sato, T. & 71 \\
Singh, S. K. & 68 \\
Helmberger, D. & 68 \\
Okal, E. A. & 67 \\
Hayakawa, M. & 61 \\
Liu, J. & 60 \\
Jackson, J. A. & 57 \\
Irikura, K. & 56 \\
Dreger, D. & 54 \\
Mori, J. & 54 \\
Hirata, N. & 52 \\
Li, Y. & 51 \\
Hartzell, S. & 50 \\
Tanioka, Y. & 50 \\
Zhang, J. & 49 \\
\hline This number does not include all articles written by each \\
author and by no means is intended to be viewed as an author \\
ranking. Updates of this table will be available at www.isc.ac \\
.uk/event_bibliography/overview.php/ or \\
.iris.washington.edu/event_bibliography/overview.php/. \\
\hline
\end{tabular}

An excerpt of output of the Event Bibliography search for the recent 11 March 2011, Tohoku earthquake is shown in Figure 4. The ISC event identifier provides a link to the ISC Bulletin data for the event (which include location parameters, magnitudes, moment tensor solutions, station data, felt report), whereas the DOI connects to the journal page of the paper. The event header line also shows the total number of publications linked to the event (Article_total) and the uppercase Event code (if available) chosen from the most recurrent name in the literature.

\section{CONCLUSIONS}

The ISC Event Bibliography associates seismic-event parameters in the ISC Bulletin to publications discussing specific events. This association allows users to perform searches based on events and/or publications parameters. The database starts with publications from the 1950s and also includes events (mostly earthquakes) from the first half of last century. Although quite extensive, this collection is not entirely comprehensive yet, and 
Search summary:

Global event search

Events between 2011-03-11 05:00:00 and 2011-03-11 06:00:00

\begin{tabular}{|c|c|c|c|c|c|c|c|}
\hline $\begin{array}{r}\text { ISC Event } \\
\underline{16461282} \\
\end{array}$ & $\begin{array}{r}\text { Agency } \\
\text { NEIC }\end{array}$ & $\begin{array}{c}\text { Origin time } \\
2011-03-11 \text { 05:46:24 }\end{array}$ & $\begin{array}{r}\text { Lat } \\
38.30\end{array}$ & $\begin{array}{r}\text { Lon } \\
142.37\end{array}$ & $\begin{array}{r}\text { Depth } \\
29.0\end{array}$ & $\begin{array}{r}\text { Magnitude } \\
\operatorname{Mw}(\mathrm{GCMT})=9.1\end{array}$ & $\begin{array}{r}\text { Article_total } \\
697\end{array}$ \\
\hline
\end{tabular}

Wang, R., Parolai, S., Ge, M., Jin, M., Walter, T.R. and Zschau, J., 2013. The 2011 Mw 9.0 Tohoku Earthquake: Comparison of GPS and Strong-Motion Data, Bull. seism. Soc. Am., 103, 2B, 1336-1347, DOI: $10.1785 / 0120110264$

Guo, A., Wang, Y., Li, Z., Ni, S., Wu, W., Liu, G., Zheng, Y. and Simons, M., 2013. Observation of Core Phase ScS from the Mw 9.0 Tohoku-Oki Earthquake with High-Rate GPS, Seismol. Res. Lett., 84, 4, 594-599, DOI: 10.1785/0220120143

Putra, P.S., Nishimura, Y., Nakamura, Y. and Yulianto, E., 2013. Sources and transportation modes of the 2011 Tohoku-Oki tsunami deposits on the central east Japan coast, Sediment. Geol., 294, 282-293, DOI: 10.1016/j.sedgeo.2013.06.004

Okal, E.A., 2013. From 3-Hz P Waves to 0S2: No Evidence of A Slow Component to the Source of the 2011 Tohoku Earthquake, Pure appl. Geophys., 170, 6-8, 963-973, DOI: $10.1007 / \mathrm{s} 00024-012-0500-\mathrm{X}$

Oguri, K., Kawamura, K., Sakaguchi, A., Toyofuku, T., Kasaya, T., Murayama, M., Fujikura, K., Glud, R.N. and Kitazato, H., 2013. Hadal disturbance in the Japan Trench induced by the 2011 Tohoku-Oki Earthquake, Sci. Rep., 3, 1915, DOI: 10.1038/srep01915

Simons, M., Minson, S.E., Sladen, A., Ortega, F., Jiang, J., Owen, S.E., Meng, L., Ampuero, J.-P., Wei, S., Chu, R., Helmberger, D.V., Kanamori, H., Hetland, E., Moore, A.W. and Webb, F.H., 2011. The 2011 magnitude 9.0 Tohoku-Oki earthquake: Mosaicking the megathrust from seconds to centuries, Science, 332, 6036, 1421-1425, DOI: $\underline{10.1126 / \text { science.1206731 }}$

Lay, T. and Kanamori, H., 2011. Insights from the great 2011 Japan earthquake, Physics Today, 64, 12, 33-39, DOI: $10.1063 /$ PT.3.1361

A Figure 4. Excerpt of a search output for the 11 March 2011 Tohoku earthquake. The header line shows the basic event parameters, with preferred hypocenter and magnitude, total number of articles and, eventually, event code. The ISC event identifier also connects to the ISC Bulletin data. References are then listed in a format accepted by many journals. The DOI links, when available, connect to the journal page of the article. Note that for this event, nearly 700 publications are available as of July 2013.

users are welcome to contribute via our submission form (www isc.ac.uk//event_bibliography/submit.php/, last accessed November 2013) or by contacting us (www.isc.ac.uk/event_ bibliography/contact.php/, last accessed November 2013).

Some 50 years of publications in various geoscience disciplines are included in the ISC Event Bibliography, and, together with the event parameters available in the ISC database since the beginning of last century, it makes the ISC Event Bibliography a useful tool both for studying seismic events in various disciplines and for facilitating the work of authors, reviewers, and journal editors during the entire process of scientific article publication. $\mathbf{z}$

\section{ACKNOWLEDGMENTS}

The ISC Event Bibliography greatly benefited from the help of journals that provided indexes and monthly notifications and the work of the ISC bibliographers, Beryl Scott-Barett and later by Peter Smith, to cover the period 1965-1995. We acknowledge Trevor I. Allen, Geological Survey of Canada, for providing us the references associated with events in the ShakeMap Atlas (Allen et al., 2009). We also acknowledge the bibliographical search of Willie Lee (USGS Emeritus), as part of the ISC-GEM Catalog preparation (founded by the GEM Foundation, www.globalquakemodel.org, last accessed November 2013), that allowed us to include about 240 references related to large earthquakes that occurred before 1979 . We gratefully acknowledge the use the Generic Mapping Tool (GMT; Wessel and Smith, 1991) in making some figures that explain the nature of the ISC Event Bibliography database. Finally, we acknowledge the support provided by NSF Grant EAR-0949072 and the ISC members.

\section{REFERENCES}

Allen, T. I., D. J. Wald, P. S. Earle, K. D. Marano, A. J. Hotovec, K. Lin, and M. G. Hearne (2009). An Atlas of ShakeMaps and population exposure catalog for earthquakes loss modeling, Bull. Earthq. Eng. 7, 707-718, doi: 10.1007/s10518-009-9120-y.

International Seismological Centre (1964-2013). ISC Bulletin, http:// www.isc.ac.uk (last accessed December 2013).

International Seismological Centre (ISC) (1965-1995). Bibliography of Seismology, annual volumes, available online at http://www.isc.ac .uk/projects/bibliography/ (last accessed December 2013).

Lee, W. H. K., and E. R. Engdahl (2013). Bibliographical search for reliable seismic moments of large earthquakes during 1900-1979 to compute $M_{\mathrm{w}}$ in the ISC-GEM Global Instrumental Reference Earthquake Catalogue, Phys. Earth Planet. In. (submitted). 
Storchak, D. A., D. Di Giacomo, I. Bondár, E. R. Engdahl, J. Harris, W. H. K. Lee, A. Villaseñor, and P. Bormann (2013). Public release of the ISC-GEM Global Instrumental earthquake catalogue (19002009), Seismol. Res. Lett. 84, no. 5, 810-815, doi: 10.1785/ 0220130034.

Wessel, P., and W. H. F. Smith (1991). Free software helps map and display data, Eos Trans. $A G U$ 72, no. 441, 445-446.

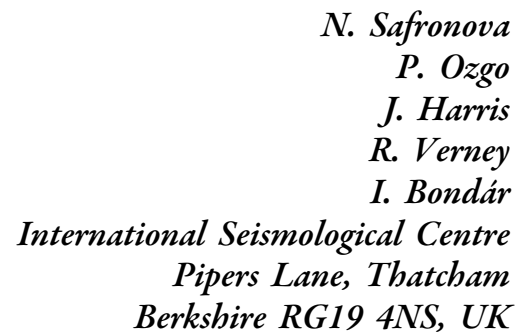

D. A. Storchak

Berkshire RG19 4NS, UK 